\title{
Impact of Front Line Demonstration on Scientific Temperament of Maize Growers in Jhabua District (M.P.)
}

\author{
Ms. Taruna Bathri \& Ms. Roshani Chouhan* Dr. Sandhya Choudhary ** \\ Dr. V.K. Swarnakar *** \\ *M.Sc. Extension Education Final Year Student 2014 \\ ** Associate Professor Extension Education, College of Agriculture, Indore \\ *** Professor \& Head Extension Education, College of Agriculture, Indore
}

\begin{abstract}
The KVK of Jhabua district (M.P.) was entrusted with the responsibility of conducting FLD in Jhabua district of M.P. The main emphasis was to maximize production per unit area by using high yielding varieties of maize in conjunction with the package and practices. While a large number of studies have been made to discuss the yield potentialities and procedures for conducting these demonstrations, limited studies have been conducted to assess the impact of FLD on knowledge and adoption level of farmers. Thus, the present study was an attempt to evaluate the impact of FLD on knowledge and adoption level of maize grower's in Jhabua district. Majority of the respondents (beneficiaries of FLD program and non-beneficiaries) possessed medium level of scientific temperament
\end{abstract}

Maize (Zea mays L.) is the third most important cereal crop of the world and India after wheat and rice. The state of Madhya Pradesh is the traditional maize growing state that covers 13 per cent of the total maize area and same as to the total maize production in the country. Maize is predominantly cultivated under rained condition in kharif season in Jhabua district of Madhya Pradesh. The productivity of maize in Madhya Pradesh is very low as compared to other maize-growing states. Average yield of maize is $18.23 \mathrm{q} / \mathrm{ha}$, average productivity of Jhabua district is $113.5 \mathrm{q} / \mathrm{ha}$ and average productivity of the state is $159 \mathrm{q} / \mathrm{ha}$. The total area under maize in MP state is 8.49 lakh ha approximate.

Front Line Demonstration (FLD) was started in maize to generate production data and feedback information to various development agencies, which are engaged in dissemination of technological advances through researchers to the farmer's fields. Increasing the productivity and improving the economic condition of the farmers, depends on the level of knowledge and skills of the farmers.

Front Line Demonstration (FLD) was started in maize to generate production data and feedback information to various development agencies, which are engaged in dissemination of technological advances through researchers to the farmer's fields.

1.1 Global ranking in maize production: Major maize growing countries and their production (million tons).

\begin{tabular}{|l|l|l|l|l|l|}
\hline Country & $\mathbf{2 0 0 7 - 0 8}$ & $\mathbf{2 0 0 8 - 0 9}$ & $\mathbf{2 0 0 9 - 1 0}$ & $\mathbf{2 0 1 0 - 1 1}$ & $\mathbf{2 0 1 1 - 1 2}$ \\
\hline \hline USA & 331.2 & 307.1 & 332.5 & 316.2 & 313.9 \\
\hline \hline China & 152.3 & 165.9 & 164.0 & 177.2 & 191.75 \\
\hline \hline Brazil & 58.6 & 51.0 & 56.1 & 57.5 & 61.0 \\
\hline \hline Argentina & 22.0 & 15.5 & 23.3 & 22.5 & 26.0 \\
\hline \hline Mexico & 23.6 & 24.2 & 20.4 & 20.6 & 20.5 \\
\hline \hline India & 19.0 & 19.7 & 16.7 & 21.3 & 21.0 \\
\hline \hline Canada & 11.6 & 10.6 & 9.6 & 11.7 & 10.7 \\
\hline \hline World & 794.9 & 799.3 & 819.4 & 828.3 & 868.06 \\
\hline
\end{tabular}

\section{Review Of Literature}

Patel and Tunver (2004) reported that the yield of groundnut was increased 24.05 per cent after FLD as compared to before frontline demonstration. It shows a positive impact of FLD on adoption of recommended practices.

Singh et al. (2005) reported that the FLD was effective in changing the attitude, skill and knowledge of improved / recommended practices of high yielding variety of rice including adoption.

Dhaka, et. al (2010) studied that the productivity of maize per unit area and time could be increased by adopting feasible scientific and sustainable management practices with a suitable variety. Taking into account the above consideration, frontline demonstrations were carried out in a systematic manner on farmers' field to 
show the worth of a new variety and convincing farmers about potentialities of improved production management practices of maize for further adoption.

Jeenger, et al., (2012) reported that majority of the respondents (beneficiaries of FLD program and non-beneficiaries) possessed medium level of scientific temperament. The scientific temperament of beneficiary farmers of FLD gave better result than the scientific temperament of non-beneficiaries.

\section{Methodology}

The present study was conducted in KVK of Jhabua District, Madhya Pradesh. During 2008-09 to 2012-13, 250 FLD maize growers were benefited by this program from the purposively selected 250 beneficiaries. About 80 beneficiary farmers from the list were selected randomly and same numbers of nonbeneficiary famers were selected randomly from the same village. Thus, 160 respondents were selected to constitute the sample of the study.

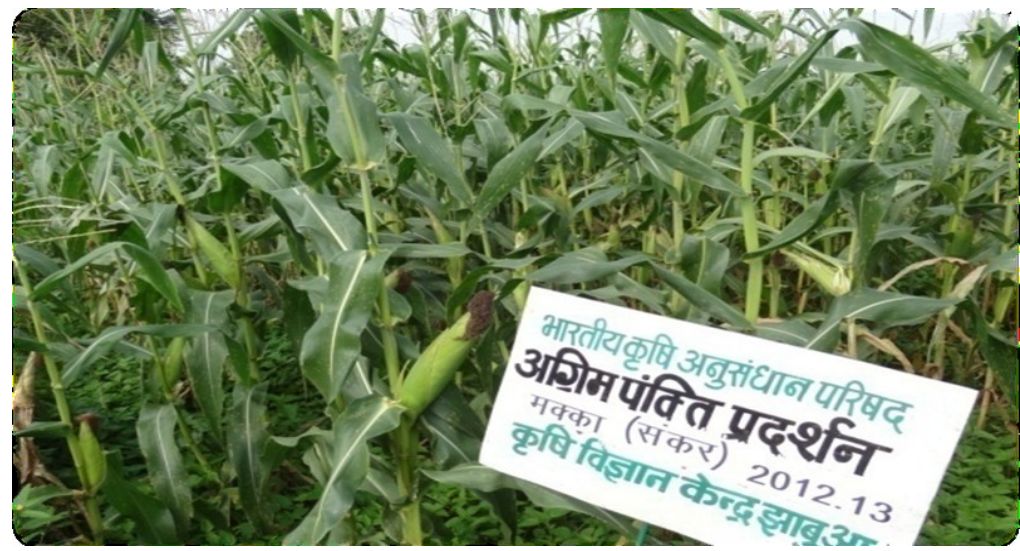

For the study purpose 8 independent variables namely age, education, farm size, irrigation potentiality, crop disciplinary, extension participation, farm mechanization, information source utilization, were selected for analyzing their association with the response variable i.e.; scientific temperament. It has been defined in this study as farmers' mental disposition related to items pertaining to four areas of human behavior vis-à-vis scientific knowledge, scientific attitude, scientific habit and utilization of scientific method. schedule,

The primary data were collected from the respondents by using a pre-tested semi- structured interview

The " $\mathrm{t}$ " test was used for testing the significant difference of mean score of two categories of the respondents in relation to their scientific temperament.

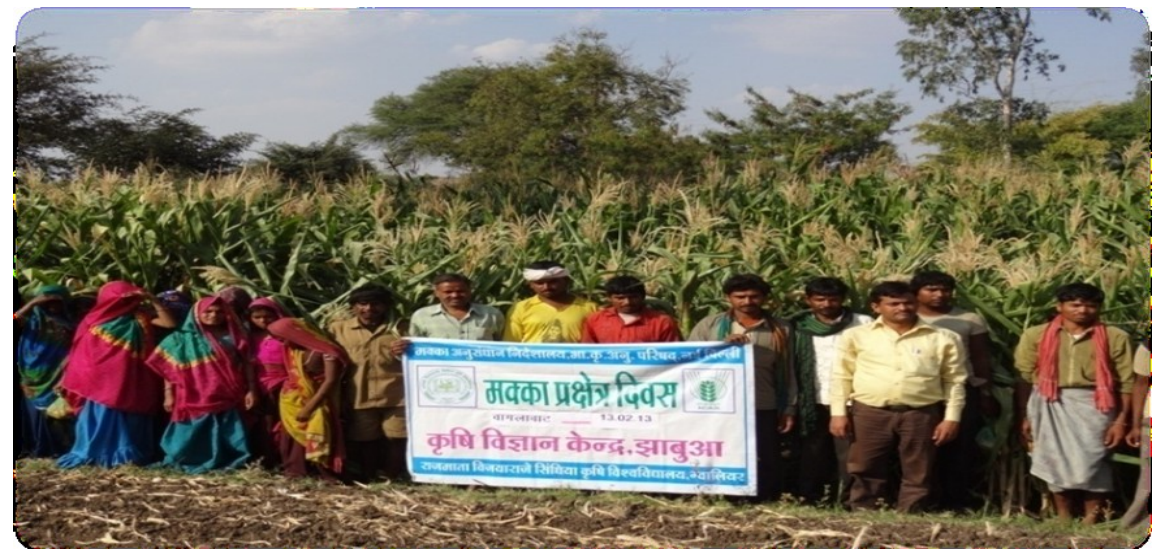

\section{Results And Discussion}

Scientific temperament of maize growers under FLD program

The scientific temperament of the maize growers under FLD program was measured with help of scientific temperament scale. Scientific temperament scale comprises of four components viz. scientific knowledge, scientific attitude, scientific habit and scientific method

The percentage distribution of the respondents according to their scientific temperament is shown in table given. The perusal of data in the table reveals that majority (53.13\%) of the respondents possessed medium level of scientific temperament, while about $(35.00 \%)$ of the respondents possessed high and 11.87 per cent 
possessed low level of scientific temperament. Similar finding was reported by De (2004) in case of potato FLD program, Patel and Tunver (2004), Singh et al. (2005), Kirar et al. (2006) and Jheenger et al. (2011).

In case of beneficiaries farmers, half (63.75\%) of the respondents had high level of scientific temperament, while 28.75 per cent had medium and only 7.50 per cent had low level of scientific temperament.

Table : Distribution of the respondents according to their scientific temperament

\begin{tabular}{|c|c|c|c|}
\hline Scientific temperament & $\begin{array}{l}\text { Beneficiaries } \\
(\mathrm{n} 1=80) \%\end{array}$ & $\begin{array}{l}\text { Non-beneficiaries } \\
(\mathrm{n} 2=80) \%\end{array}$ & $\begin{array}{l}\text { Total } \\
(\mathrm{n}=160) \%\end{array}$ \\
\hline Low $(<64.14)$ & $6(7.50)$ & $13(16.25)$ & 19 (11.87) \\
\hline Medium (64.14-82.11) & $23(28.75)$ & $62(77.50)$ & $85(53.13)$ \\
\hline High (>82.11) & $51(63.75)$ & $5(6.25)$ & $56(35.00)$ \\
\hline Total & 80(100.00) & 80(100.00) & $186(100.00)$ \\
\hline Mean & 71.12 & 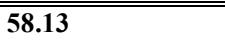 & 69.51 \\
\hline \multirow[t]{2}{*}{ Sd } & 12.11 & 6.57 & 7.26 \\
\hline & & & $t^{\prime} t^{\prime}=12.41 * *$ \\
\hline
\end{tabular}

In case of non-beneficiary farmers, 77.50 per cent had medium level of scientific temperament, while, 16.25 per cent had low and only 6.25 per cent had high level of scientific temperament.

The table also presents the data regarding mean scientific temperament of the farmers. The data indicated that mean scientific temperament of total respondents was 69.51. The data also indicated that mean value of scientific temperament of beneficiary farmers of FLD was higher (71.12) than the mean score (58.13) of scientific temperament of non-beneficiaries.

The ' $t$ ' test was used for testing the significant difference of mean score of scientific temperament of two groups (beneficiaries of FLD program and non-beneficiaries) by applying " $\mathrm{t}$ " test in context with the scientific temperament. The found value of " $t$ " test (12.41) is highly significant at .01 level of significance with df 158, it shows that the scientific temperament of beneficiaries of maize FLD was found to be more benefitted in comparison to non beneficiaries of maize cultivators. It shows that the KVK, Jhabua, have given specific attention on knowledge and adoption of improved maize farming through FLD and they are more technically sound on their cropping and acquired high knowledge and adoption about the scientifically as proved by the scientist.

The hypothesis under this test was that the beneficiaries of FLD program and non beneficiaries differ in their degree of scientific temperament.

Table : Percentage of Operationalization of Scientific Temperament$(\mathrm{N}=160)$

\begin{tabular}{|c|c|c|c|c|}
\hline $\begin{array}{l}\begin{array}{l}\text { Operationalization } \\
\text { temperament }\end{array} \\
\text { of }\end{array}$ & $\mathbf{F}$ & $\begin{array}{l}\text { Beneficiaries } \\
(\mathrm{N}=\mathbf{8 0}) \%\end{array}$ & $\mathbf{F}$ & $\begin{array}{l}\text { Non-beneficiaries } \\
(\mathrm{N}=\mathbf{8 0}) \%\end{array}$ \\
\hline Scientific knowledge & 75 & 94.00 & 34 & 42.00 \\
\hline Scientific Attitude & 73 & 91.00 & 39 & 48.00 \\
\hline Utilization of scientific methods & 72 & 90.00 & 32 & 39.00 \\
\hline Scientific habit & 65 & 82.00 & 25 & 30.00 \\
\hline
\end{tabular}

Data in table clearly indicates that, beneficiaries farmers had more scientific knowledge (94\%), scientific attitude $(91 \%)$, utilization of scientific methods $(90 \%)$ and scientific habit $(82 \%)$ compared to nonbeneficiaries farmers scientific knowledge (42\%), scientific attitude (48\%) utilization of scientific methods $(39 \%)$ and scientific habit $(30 \%)$. Kubde et al. (1999) revealed that cent per cent respondents were aware about the improved variety.

\section{Conclusion}

Majority of the respondents possessed medium level of scientific temperament. The mean value of scientific temperament of beneficiary farmers of FLD was higher than the mean score of scientific temperament of non-beneficiaries. The " $t$ " test indicated that there is a significant difference between scores mean of both the group. Thus, it can be stated that, there is an impact of FLD program on scientific temperament of the maize growers. 


\section{References}

[1]. Dhaka, B.L.; Meena, B.S. and R. L. Suwalka, (2010). Popularization of Improved Maize Production Technology through Frontline Demonstrations in South-eastern Rajasthan J Agri Sci, 1(1): 39-42.

[2]. Jeenger, K.C.; Choudhary, S. and Swarnakar, V.K. (2012). Impact of frontline demonstration on scientific temperament of soybean growers in Dhar districts of Madhya Pradesh. (IOSR-JAVS) Volume 1, Issue 4pp47-48,

[3]. Kadam, R.P.; Wangikar, S.D. Pawar, G.S. and Bhosale, P.B. (2005). Knowledge level of farmers about improved soybean production technology, J. Soil Crops, 15 (1): 210-212

[4]. Kirar, K.S.; Impact of technological practices on the productivity of soybean in front line demonstration. Indn. J. Extn. Edu. $5: 11$.

[5]. Patel, A.J.; and Tunver, M.A. (2004). Evaluation of frontline demonstration on groundnut. Gujarat J. Extn. Edun. 15 (1): $77-79$ 